\title{
Vazão de pico em uma bacia hidrográfica com diferentes níveis de urbanização em Santarém/PA
}

Os efeitos da urbanização sobre o aumento da vazão de pico e escoamento superficial da bacia hidrográfica do igarapé do Urumari em Santarém/PA foram analisados. O uso do solo é determinante para o dimensionamento da rede de drenagem pluvial, tendo em vista que as áreas mais impermeabilizadas acarretam maior escoamento superficial e vazão de pico. Assim, foram simulados três cenários de uso do solo: 1960, 2017 e um cenário futuro. Foram determinadas as porcentagens de área impermeabilizada de cada época, através de mapas gerados em ambiente SIG, imagens de satélite e adaptação de mapas no software DraftSight 2018. A partir do método SCS (Soil Conservation Service), calcularam-se os parâmetros necessários para a geração dos hidrogramas de cheia dos três cenários. Os resultados mostraram que o processo de urbanização tem efeito significativo sobre as vazões de pico de bacias hidrográficas urbanas, o que pode ser visto claramente nos hidrogramas de cheia apresentados. Nesse caso, o cenário futuro, por ter maior impermeabilização do solo, apresentou uma vazão de pico 2,24 vezes maior que a vazão de pico do cenário de 2017 e 6,80 vezes maior que a do cenário de 1960 . Esses resultados servem de alerta para os gestores municipais no que se refere ao planejamento e controle das políticas urbanas em relação à rede de drenagem de águas pluviais, que deve ser norteada em concordância com os estudos da expansão urbana.

Palavras-chave: Hidrograma de Cheia; Vazão de Pico; Escoamento Superficial; Impermeabilização do Solo.

\section{Peak flow in a catchment with different levels of urbanization in Santarém/PA}

\begin{abstract}
The effects of urbanization on the increase of the peak flow and surface runoff of the Urumari catchment in Santarém/PA were analyzed. The use of the soil is determinant for the dimensioning of the rainwater drainage network, considering that the more soil sealing areas lead to greater surface flow and peak flow. Thus, three scenarios of use of the soil were simulated: 1960, 2017 and a future scenario. The percentages of waterproofed area of each period were determined through maps generated in GIS environment, satellite images and map adaptation in the DraftSight 2018 software. The necessary parameters for the generation of the flood hydrograms of the three scenarios were determined from the SCS (Soil Conservation Service) method. The results showed that the urbanization process has a significant effect on the peak flows of urban hydrographic basins, which can be clearly seen in the presented hydrograms. In this case, the future scenario, due to greater soil sealing, presented a peak flow 2.24 times greater than the peak flow of the 2017 scenario and 6.80 times greater than those of the 1960 scenario. These results serve as an alert for municipal managers in the planning and control of urban policies in relation to the rainwater drainage network, which should be guided by studies of urban expansion.
\end{abstract}

Keywords: Hydrogram Of Flood; Peak Flow; Surface Runoff; Soil Sealing.

Topic: Engenharia de Recursos Hídricos

Reviewed anonymously in the process of blind peer.
Received: 10/08/2018

Approved: 24/09/2018
Luciana Lavareda Rodrigues

Universidade Federal do Oeste do Pará, Brasil

http://lattes.cnpq.br/3184721630772472

lucianalavareda@hotmail.com

Claudio José Cavalcante Blanco id

Universidade Federal do Pará, Brasil

http://lattes.cnpq.br/8319326553139808

http://orcid.org/0000-0001-8022-2647

blancocjc@outlook.com
Referencing this:

RODRIGUES, L. L.; BLANCO, C. J. C.. Vazão de pico em uma bacia hidrográfica com diferentes níveis de urbanização em Santarém/PA. Revista Ibero Americana de Ciências Ambientais, v.9, n.7, p.62-75, 2018. DOI: http://doi.org/10.6008/CBPC2179-6858.2018.007.0007 


\section{INTRODUÇÃO}

A impermeabilização excessiva do solo é uma característica comum das cidades, principalmente nas áreas centrais, contudo é uma característica preocupante, pois aliada a um sistema de drenagem insuficiente torna-se um dos principais fatores que causam alagamentos de ruas e prejuízos aos moradores em geral. Barros et al. (2016) dizem que devido ao processo de urbanização das áreas urbanas dos Estados Unidos e Europa na década de 1960, os estudos sobre os impactos da impermeabilização intensificaram-se naquele período e estudos mais recentes tendem a confirmar o que diz a teoria hidrológica convencional, ou seja, que o escoamento superficial aumenta juntamente com o crescimento da urbanização e impermeabilização do solo.

Justino et al. (2011) também abordaram a influência direta do uso do solo sobre a resposta hidrológica das bacias hidrográficas, apresentando como resultados mais evidentes o aumento do volume de escoamento superficial, o aumento da vazão de pico e a redução do potencial de infiltração, gerando a ocorrência de alagamentos. Segundo Freitas et al. (2012), o processo de urbanização provoca alteração no ciclo hidrológico das bacias hidrográficas causando principalmente aumento do escoamento superficial, aumento da ocorrência de inundações e aumento na vazão de pico em um menor intervalo de tempo, ocasionando alteração dos hidrogramas.

Diversos trabalhos abordando o impacto da urbanização sobre a vazão de pico e o aumento do volume de escoamento superficial em bacias hidrográficas já foram realizados, por exemplo: Nunes et al. (2008) utilizaram a adaptação do Método Racional para analisar os impactos do processo de urbanização sobre o sistema de drenagem da bacia hidrográfica do rio Atuba, estado do Paraná. Os autores levaram em consideração o tipo do solo, a declividade do terreno, o tempo de concentração e variabilidade espacial da precipitação para os anos de 1962, 1980 e 2000 e com a técnica de fotointerpretação, simularam uma projeção de dados para o ano de 2020. Os resultados deixaram clara a correlação entre impermeabilização do solo, aumento da vazão de pico e aumento do escoamento superficial. Justino et al. (2011) também estudaram o efeito da impermeabilização do solo sobre o escoamento superficial, através da simulação da evolução da urbanização da bacia do Córrego Lagoinha em Uberlândia-MG, simulando quatro cenários, Préurbanização, atual, futuro I e futuro II, tendo como referência o cenário Pré-urbanização.

Utilizando hidrogramas de vazão para a simulação do efeito da impermeabilização sobre o aumento do escoamento superficial, pelo Método SCS TR-55 (Soil Conservation Service - Technical Release 55), mostraram que a vazão de pico pode aumentar em até 60 \% num cenário onde a impermeabilização varia entre 29 e 54 \%. Bianchi et al. (2012) avaliaram através do método Ven Te Chow - Soil Conservation Service (SCS), a vazão máxima estimada para os anos de 1976, 1984 e 2009 da bacia hidrográfica do rio Canguiri, localizada na região metropolitana de Curitiba. Os resultados mostraram que o aumento da urbanização no período de 1976 a 2009, assim como o avanço da agricultura e a diminuição das áreas de florestas, incidiram diretamente no aumento das vazões de pico, devido ao aumento do escoamento superficial. Faria et al. (2014) analisaram três diferentes cenários de impermeabilização, num período de 2 a 100 anos, sendo um 
atual e dois futuros na bacia hidrográfica do córrego Barbado, localizada no perímetro urbano do município de Cuiabá-MT. No primeiro cenário, considerou-se a condição atual da bacia; no segundo cenário, simulouse a ocupação dos lotes atualmente vazios; e no terceiro cenário, simulou-se a impermeabilização do solo de toda a bacia com a mesma taxa de impermeabilização característica de áreas centrais. Os autores concluíram que os cenários, nos quais a taxa de impermeabilização aumentou, tiveram também aumento das vazões de pico.

Benini et al. (2015) compararam quatro cenários de diferentes períodos de urbanização da Bacia do Córrego do Mineirinho, localizada em São Carlos-SP, objetivando analisar o efeito do processo de impermeabilização do solo causada pela implantação do campus 2 da USP, sobre o ciclo hidrológico. Assim, simularam: um cenário Pré-urbanização, um cenário antes da implantação do campus no ano 2000 e dois cenários hipotéticos, sendo um o cenário no ano 2025 sem implantação de Plano Diretor, portanto com um processo de urbanização sem normas e sem diretrizes e outro cenário no ano 2025 , seguindo as diretrizes do Plano Diretor Municipal e do Plano Diretor de Ocupação (PDO) do campus 2 da USP.

Os resultados mostraram que a taxa de impermeabilização do solo junto com a redução das áreas com cobertura vegetal, aumentaram as vazões máximas e diminuíram o tempo de pico, com maior diferença entre os cenários dos anos 1972 e 2000 e menor diferença entre os cenários hipotéticos do ano 2025, com e sem Plano Diretor (PD). Barros et al. (2016) mostram, a partir da análise de dois cenários da bacia urbana do riacho do Sapo em Maceió/AL, como as diversas características da cobertura superficial do solo influenciam na variação de geração de escoamento. Os dois cenários referem-se, respectivamente, a setembro de 2002 e novembro de 2010. Os autores concluíram que a impermeabilização do solo, ocorrido entre os cenários, influência de forma significativa a vazão de pico e o volume de escoamento superficial.

Santos et al. (2017) contextualizaram a problemática da sobrecarga do sistema de drenagem provocada pela impermeabilização urbana, através da análise do uso do solo num período de 32 anos, nos bairros Catolé e Sandra Cavalcante, em Campina Grande-PB. Os resultados mostraram que a sobrecarga no sistema de microdrenagem decorreu do aumento do escoamento superficial causado pela impermeabilização do solo e que esta é causada pela falta de planejamento urbano nesses bairros, apesar de existir legislação e diretrizes que orientem o zoneamento.

A cidade de Santarém, localizada no Oeste do estado do Pará, é objeto deste estudo por contar com áreas bastante urbanizadas e outras com infraestrutura precária. O que se explica pela cidade ser mononuclear, sendo aquelas onde a área central é mais densa, enquanto as áreas periféricas apresentam urbanização média e fraca, pois mais ao centro localizam-se os serviços e comércios, aumentando a taxa de ocupação (REZENDE et al., 2015). Em Santarém, o período de chuvas é marcado por muitos transtornos, prejudicando a mobilidade de veículos e pedestres, assim como interferindo negativamente nas atividades comerciais, institucionais e educacionais nas áreas afetadas.

Diversos métodos são utilizados para analisar o impacto da urbanização e sua evolução sobre o aumento da vazão de pico e volume de escoamento. Segundo Barros et al. (2016), a análise de bacias similares com diferentes graus de urbanização é um dos métodos utilizados. Seguindo essa ideia, propõe-se 
neste trabalho analisar a vazão de pico de três cenários com diferentes níveis de urbanização da pequena bacia hidrográfica urbana do igarapé do Urumari, Santarém/PA, simulando o grau de urbanização no passado, presente e futuro, procurando mostrar através de hidrogramas de cheia, o impacto da impermeabilização do solo na resposta hidrológica da bacia.

\section{REVISÃO TEÓRICA}

\section{Caracterização da área estudada}

A área de estudo é a bacia hidrográfica do igarapé do Urumari (Figura 1), localizada em área urbana da cidade de Santarém/PA, entre as coordenadas $2^{\circ} 25^{\prime} 0^{\prime \prime}$ e $2^{\circ} 31^{\prime} 0^{\prime \prime}$ de latitude Sul e $54^{\circ} 44^{\prime} 0^{\prime \prime}$ e $54^{\circ} 40^{\prime} 0^{\prime \prime}$ de longitude oeste, possuindo uma área de $27,04 \mathrm{~km}^{2}$. Essa bacia apresenta em aproximadamente $62 \%$ do total de sua área, alta impermeabilização do solo, sendo esta a parte da bacia que possui maior infraestrutura e serviços públicos. Rayol et al. (2015) descreve que o clima de Santarém é quente e úmido com temperatura máxima de 30 a $33^{\circ} \mathrm{C}$ e mínima de 21,9 a $23,1^{\circ} \mathrm{C}$. A umidade relativa do ar varia de $78 \%$ a $89 \%$ e a precipitação total anual é em torno de $2098 \mathrm{~mm}$, com variação de $39 \mathrm{~mm}$ nos meses mais secos e $358 \mathrm{~mm}$ nos meses mais chuvosos, apresentando um período de estiagem de 3 a 4 meses (agosto a novembro).

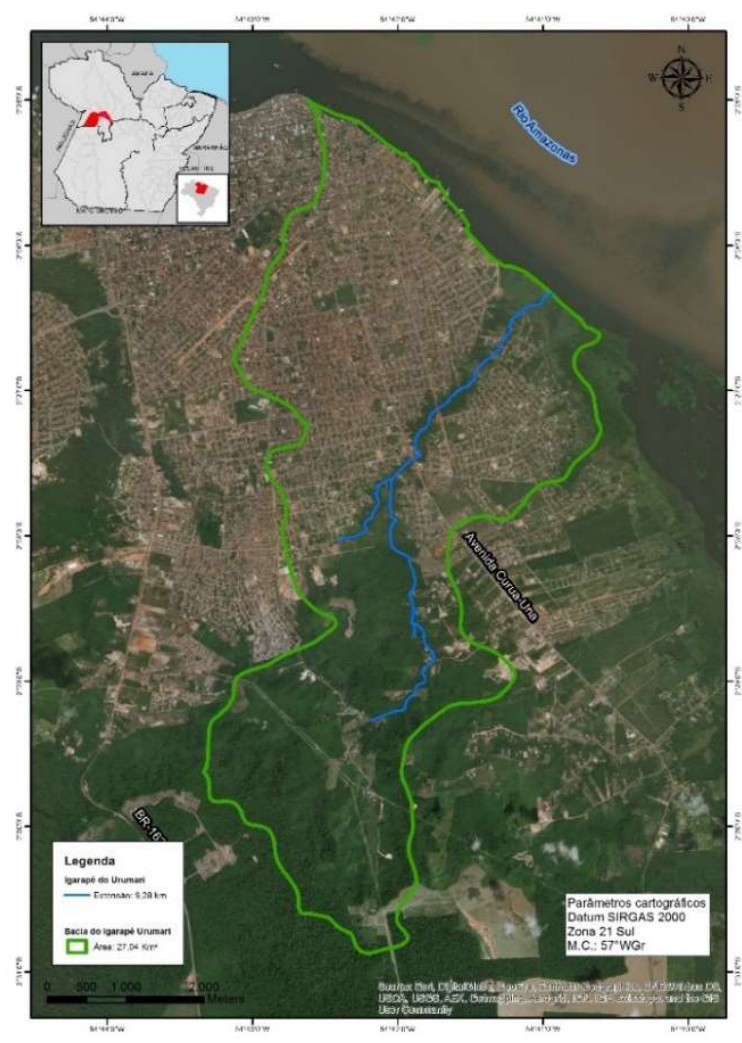

Figura 1: Imagem de satélite mostrando o cenário 2017 da área estudada com diferentes níveis de urbanização.

O centro da cidade de Santarém, como na maioria das cidades brasileiras, concentra a melhor infraestrutura, pois foi reordenado a partir da década de 1960, no período militar, quando se fizeram presentes políticas de saneamento básico e fora construída uma rede coletora de águas pluviais que, ainda segundo Ferreira (2016), abrangia 40\% da cidade à época. Pimentel et al. (2014), explicam que até o final da década de 1970, em virtude da localização dos igarapés Urumari, a leste e Irurá, a oeste, a expansão urbana 
de Santarém dava-se apenas no sentido sul da cidade e que a partir da década de 1980, a expansão avança e ultrapassa os igarapés que serviam de obstáculo. Oliveira (2008) também aborda o histórico de que, desde a década de 1980, Santarém passa por um processo de expansão urbana (Figura 2), que vem assumindo grandes proporções, ocasionando o espraiamento de sua periferia no sentido da Rodovia 163 (CuiabáSantarém) e Rodovia PA 370 (Santarém-Curuá-Una). Entretanto, mais de cinco décadas após o início da expansão, muito das áreas expandidas ainda continuam sem a devida inclusão dos serviços de infraestrutura básica e desenvolvimento urbano, acarretando problemas previsíveis, como alagamentos de ruas.

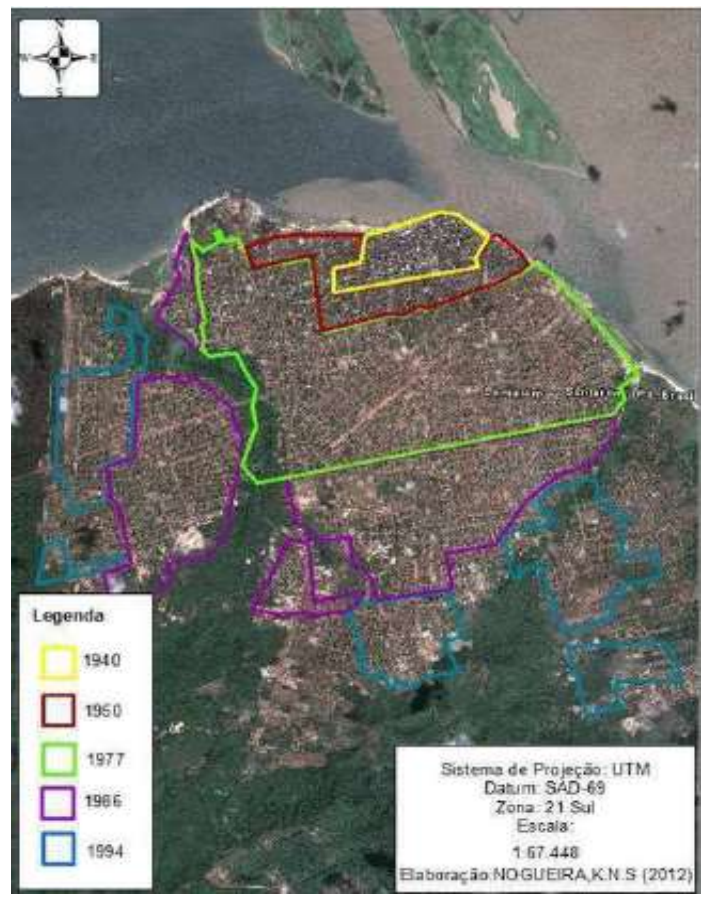

Figura2: Mapa da Expansão Urbana de Santarém (1940-1994). Fonte: Ferreira (2016).

A vegetação encontra-se muito alterada na bacia do igarapé do Urumari, que vem passando por intensa degradação ambiental devido às ações antrópicas, como relatam Pimentel et al. (2014): despejo de resíduos sólidos (lixo), lançamento de efluentes por galerias, assoreamento por construção de obras públicas, desmatamento e queimadas. O solo da bacia é predominante do tipo Argissolo Amarelo Distrófico típico A, moderado com textura média argilosa de floresta equatorial subperenifólia, possuindo relevo ondulado a forte ondulado. Percebe-se também o tipo Latossolo Amarelo Distrofico típico A, moderado com textura muito argilosa de floresta equatorial subperenifólia de relevo suave a ondulado (SANTOS et al., 2002).

\section{MATERIAIS E MÉTODOS}

Este trabalho é baseado na determinação e análise de hidrogramas de cheia para três diferentes cenários de urbanização da bacia do Urumari (Figura 3). Assim, foram analisados 3 cenários; o primeiro (1960), no qual o nível de urbanização da bacia hidrográfica ainda era baixo; o segundo (2017), mais recente, no qual a bacia apresenta um nível médio de urbanização; e o terceiro, cenário futuro, simulando um alto 
nível de urbanização, considerando o que está previsto no Plano Diretor Participativo do município de Santarém.

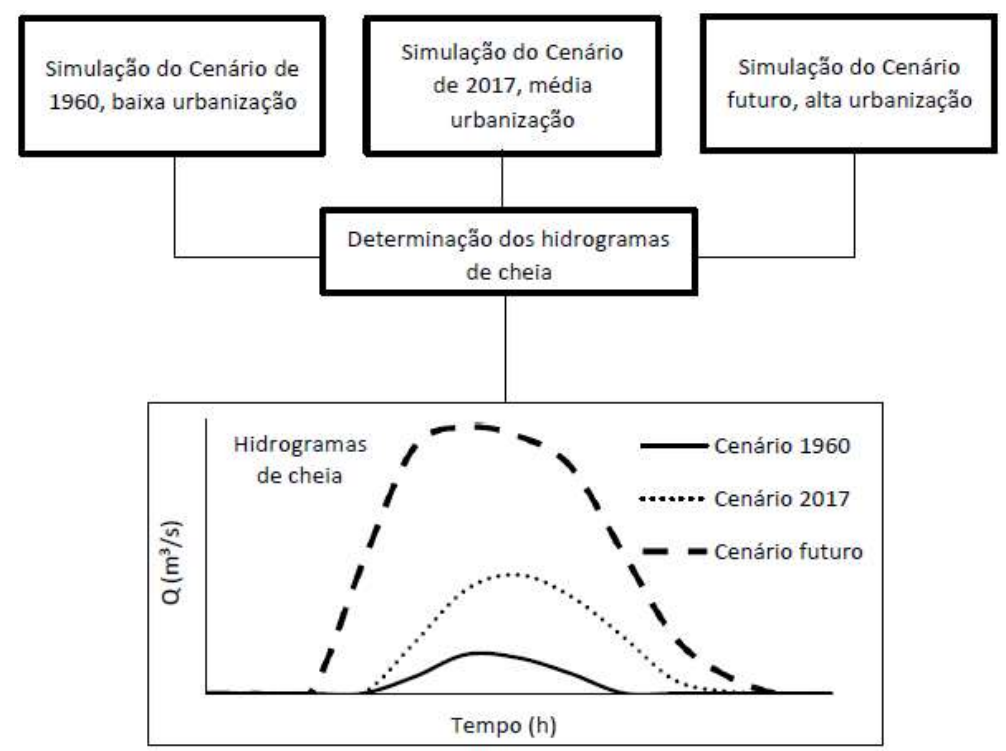

Figura 3: Esquema resumido da metodologia.

\section{Dados do terreno}

A delimitação da bacia hidrográfica foi realizada em um ambiente SIG (Sistema de Informações Geográficas) de forma foto-interpretativa, usando o modelo digital de terreno (MDT) do programa SRTM. A obtenção de dados topográficos, mais especificamente dos dados altimétricos, foi feita a partir de imagens do programa SRTM (Shuttle Radar Topography Mission - https://Ita.cr.usgs.gov/SRTM) com uma resolução espacial de $90 \mathrm{~m}$. A extração do leito do igarapé foi digitalizada através de imagens de satélite e cartas topográficas na escala de 1:100.000 (Carta MI-0528 obtida no site do Departamento de Serviço Geográfico do Exército $\left.{ }^{1}\right)$.

As cotas altimétricas para o cálculo de declividade do leito do igarapé foram extraídas do MDT já citado, partindo da nascente do igarapé e intercaladas entre si por uma distância de 1000 metros até a foz do mesmo. Assim, a declividade foi determinada baseada na diferença de um ponto ao outro. As imagens de satélite foram obtidas através do programa Google Earth, 2017, Google Maps e a adaptação de alguns mapas foram confeccionados através do software DraftSight 2018. Dessa forma, foram determinados: a área de drenagem da bacia, sendo igual a $27,04 \mathrm{~km}^{2}$; o talvegue principal com 9,28 km; e a declividade de 5,82 m/km.

\section{Dados de chuva}

Os dados de chuva utilizados, para determinação dos hidrogramas de cheia, são oriundos da estação meteorológica automática: Santarém-A250, Código OMM: 81707, Registro: 21 UTC, inaugurada em: 02/09/2015, Latitude: -2.502572으, Longitude: -54.720279, Altitude: 137 metros. Dos dados horários das precipitações pluviométricas disponibilizados pelo INMET, foi selecionado o evento do dia 11 de março de

\footnotetext{
${ }^{1}$ http://www.dsg.eb.mil.br 
2017, com duração de 5 horas, no horário das 5 h às $10 \mathrm{~h}$ e com precipitação total de $137,8 \mathrm{~mm}$. Este evento foi selecionado dentro de um período em que não ocorreu chuva anterior, pois segundo ALMEIDA et al. (2013), a não ocorrência de precipitação antecedente é fator climático importante para seleção do evento, uma vez que a precipitação que ocorre sobre o solo umedecido tem maior facilidade de escoamento, levando à estimativa de tempo de concentração inferior ao determinado para o solo seco. Na Figura 4 é mostrado o hietograma da chuva selecionada e a discretização temporal de 1 hora.

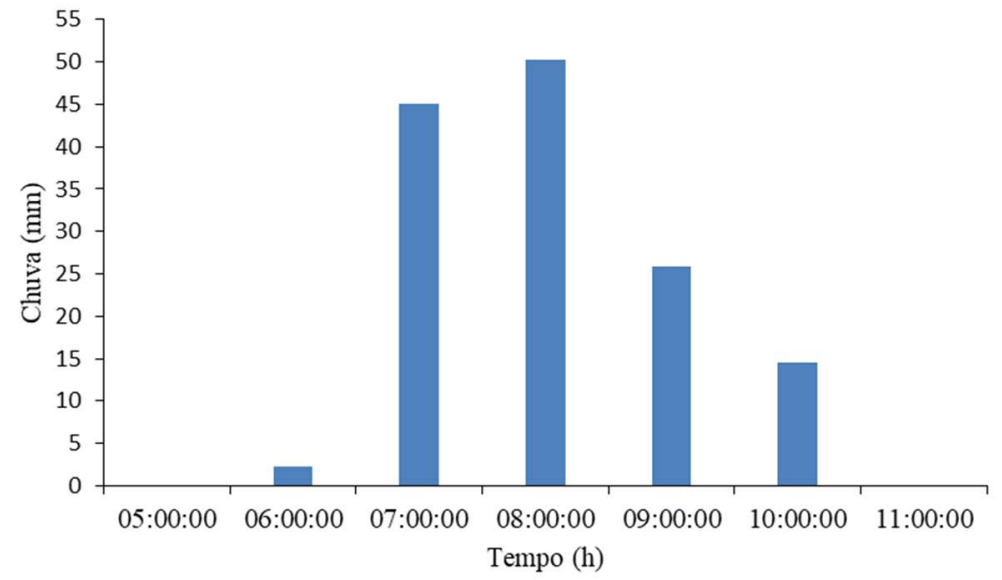

Figura 4: Hietograma da chuva selecionada.

\section{Hidrograma de cheia}

A determinação dos hidrogramas de cheia para os diferentes cenários, foram elaborados através do método SCS (Soil Conservation Service) para um determinado evento de chuva escolhido conforme sua duração e intensidade. O método da Curva Número, ou SCS, tem seu uso é apropriado para bacias de tamanho médio, aqui definido como sendo aquelas com áreas entre $2,5 \mathrm{~km}^{2}$ e $100 \mathrm{~km}^{2}$ (FERNANDES et al., 2017). Optou-se pelo uso deste método, pois além da área de drenagem da bacia enquadrar-se no mesmo, ele considera ainda, o uso e ocupação do solo, que são fatores determinantes para os estudos sobre os impactos da urbanização em bacias hidrográficas. O método do SCS é baseado no cálculo de Pef (Equação 1).

$$
\text { Pef }=\frac{(\mathrm{P}-0,2 . \mathrm{S})^{2}}{\mathrm{P}+0,8 . \mathrm{S}}
$$

A Equação 1 é válida para $\mathrm{P}>\mathrm{Al}$, onde $A l=0$,2.S. Al (Abstração Inicial) representa todas as perdas antes do início do escoamento, incluindo a água retida nas depressões do terreno, a água infiltrada, interceptada pela vegetação ou ainda evaporada. Dessa forma, Pef é a precipitação efetiva, ou escoamento superficial, ou chuva excedente ou ainda Runnof; P é a precipitação unitária, por hora (mm); e S é o potencial de infiltração, que pelo método do SCS, é calculado pela Equação 2.

$$
S=\frac{25400}{\mathrm{CN}}-254
$$

Onde $\mathrm{CN}$ é o número de curva, que é um parâmetro hidrológico usado para descrever o potencial de escoamento das águas pluviais para áreas de drenagem, e é uma função do uso da terra, do tipo de solo e umidade (FERNANDES et al., 2017). Existem tabelas para bacias rurais e urbanas, nas quais se combinando os três fatores e se obtém i valor de CN. Neste trabalho foi proposta uma tabela simplificada utilizando os valores de CN para bacias urbanas e suburbanas de Santos et al. (2016). 
Tabela 1: Número de curva CN do SCS.

\begin{tabular}{|c|c|c|c|c|c|}
\hline Uso do solo & Superfície & A & B & C & D \\
\hline Floresta & Normal & 36 & 60 & 70 & 76 \\
\hline Impermeável & Arruamentos e estradas asfaltadas e com drenagem pluvial & 98 & 98 & 98 & 98 \\
\hline
\end{tabular}

Foi necessário determinar o valor de CN para os três diferentes cenários: 1960, 2017 e futuro. Para o CN de 1960, foi utilizado como base o mapa da expansão urbana (Figura 2). Assim, através do software DraftSight 2018 adaptou-se um mapa da expansão urbana da bacia do Urumari (Figura 5), determinando-se assim, a área igual a $0,80 \mathrm{~km}^{2}$ e o percentual de impermeabilização igual a 2,96 \% do total de sua área. Deste modo, como a parcela de área impermeável não é considerável, pôde-se definir o $\mathrm{CN}$ utilizando diretamente a Tabela 1, identificando seu tipo e ocupação do solo, enquadrando-se no grupo C e cobertura tipo floresta, ou seja, CN igual a 70.

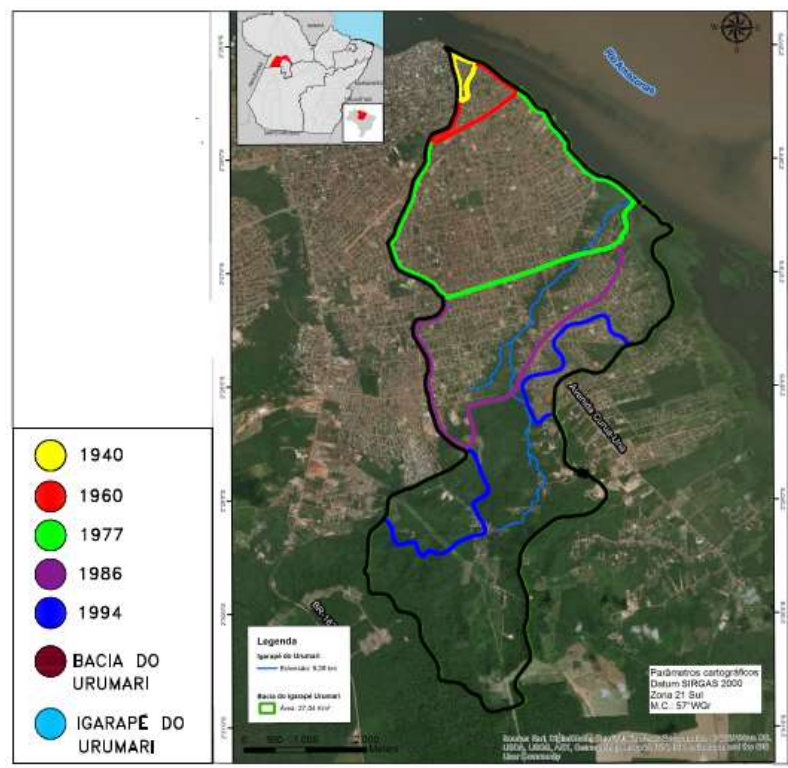

Figura 5: Mapa da expansão urbana da bacia hidrográfica do igarapé Urumari.

Para a determinação do $\mathrm{CN}$ do cenário de 2017 , foi considerado o uso misto da bacia do igarapé Urumari com áreas urbanizadas e impermeabilizadas e outras sem urbanização e pavimentação. Sua parte urbanizada em 2017 correspondia a mais de 60 \% da área total de drenagem, neste caso o índice foi calculado como CNc composto (CNc - Equação 3), conforme Chang et al. (2015).

$$
\mathrm{CNc}=\mathrm{Ap} \cdot \mathrm{CNp}+\mathrm{Ai} \cdot \mathrm{CNi}
$$

Onde CNc é o número de curva composto da bacia urbana em estudo; Ap é a porcentagem de área permeável; CNp é número de curva da área permeável (Tabela 1); Ai é a porcentagem de área impermeável; e CNi é o número curva da área impermeável (Tabela 1).

Neste cenário, sua área mais urbanizada e impermeável, corresponde a $16,70 \mathrm{~km}^{2}$, o que equivale a $61,76 \%$ da área de drenagem $\left(27,04 \mathrm{~km}^{2}\right)$, para cálculo do $\mathrm{CNc}$, considerou-se o arredondamento para $\mathrm{Ai}=$ $62 \%$ como fração da área impermeável, resultando em Ap igual a 38\%. O tipo de solo de sua área permeável foi considerado conforme o mapa de reconhecimento dos solos do planalto de Santarém (SANTOS et al., 2002). Pela Tabela 1, a área permeável da bacia do Urumari, corresponde ao grupo C e cobertura tipo floresta. Então, adotou-se para sua área mais permeável CNp igual a 70. Assim, os valores de CNp e CNi foram aplicados à Equação 3, resultando em CNc igual a aproximadamente 87. Para o cenário futuro, foi feita uma simulação baseada no que diz a Lei de Parcelamento, Uso e Ocupação do Solo, do município de Santarém 
(Lei Complementar 007/2012 de 28 de setembro de 2012). Assim, foi utilizado como base o Mapa de Zoneamento Urbano, apresentado na Figura 6 e, através do software DraftSight 2018, adaptou-se um mapa de zoneamento da bacia do Urumari (Figura 7).

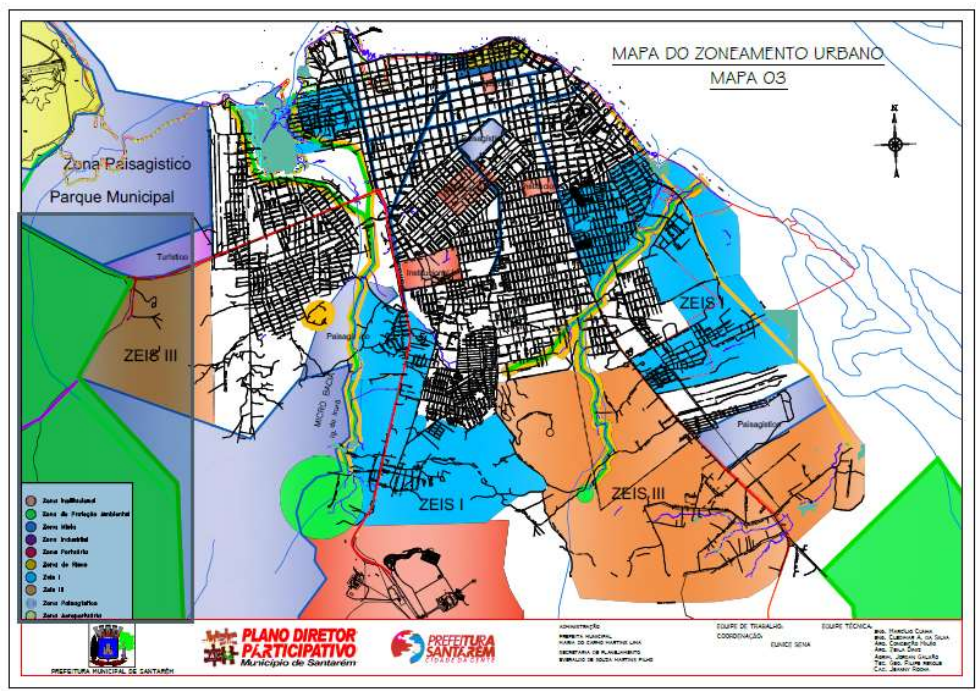

Figura 6: Mapa de Zoneamento Urbano. Fonte: Santarém, 2012.



Figura 7: Mapa de zoneamento da bacia do Urumari.

De acordo com essa Lei, o Município de Santarém tem o seu perímetro urbano dividido em onze zonas individualizadas, porém neste trabalho vamos nos ater apenas nas porções que estão dentro da área da bacia do Urumari, que são as ZEIS (Zonas Especiais de Interesse Social) I e III. O uso do solo dessas zonas é determinado no Art. 54, da referida Lei, na qual está previsto que essas zonas podem ser beneficiadas com conjuntos habitacionais e mutirões habitacionais, que podem ser inseridos nas Zonas Residenciais (ZR1) ou (ZER) em conformidade com os parâmetros urbanísticos definidos na Lei. Os parâmetros urbanísticos 
definem que nas zonas residenciais o percentual obrigatório de área permeável é de $10 \%$, portanto, foi considerado que o percentual de impermeabilização do solo para o cenário futuro é de $90 \%$. De acordo com a Tabela 1 o CN para cenário futuro é 98. Após determinação dos CN, foram determinados, pelas Equações 4, 5 e 6, respectivamente, tempo de pico (Tp), vazão de pico (Qp) e o tempo de concentração (Tc).

$$
\mathrm{Tp}=\mathrm{Tr} / 2+0,6 \cdot \mathrm{Tc}
$$

Onde Tp é o tempo de pico (h); Tr é o tempo de duração da precipitação unitária (h); e Tc é o tempo de concentração

$$
Q p=\frac{0,208 \cdot \mathrm{A}}{\mathrm{Tp}}
$$

Onde Qp é a vazão de pico $\left(\mathrm{m}^{3} / \mathrm{s}\right)$; A é a área de drenagem da bacia $\left(\mathrm{km}^{2}\right)$; e Tp é o tempo de pico (h). A literatura apresenta várias fórmulas para calcular o Tempo de Concentração (Tc) de uma bacia.

Neste trabalho optou-se pelo método de Germano et al. (1998), que estudaram o comportamento hidrológico de 28 bacias brasileiras urbanas de médio porte, estabelecendo correlações entre o comprimento destas bacias e a percentagem de suas áreas impermeáveis, obtendo-se a Equação 6, que considera o grau de impermeabilização da bacia, sendo que esse é um importante fator para este estudo, tendo em vista os diferentes níveis de urbanização da área estudada.

$$
T c=18,628\left(\frac{L^{0,882}}{i m p^{0,272}}\right)
$$

Onde Tc é o tempo de concentração da bacia (min); L é o comprimento do talvegue principal (km); e imp é a porcentagem de área impermeável na bacia (\%).

\section{RESULTADOS E DISCUSSÃO}

\section{Parâmetros encontrados para os diferentes cenários}

Com a metodologia analisada, foram determinados os parâmetros para simulação dos hidrogramas de cheia segundo o método do SCS para os diferentes cenários (Tabela 2).

\begin{tabular}{|c|c|c|c|}
\hline & Cenários & & \\
\hline & 1960 & 2017 & Futuro \\
\hline Área de drenagem $\left(\mathrm{km}^{2}\right)$ & 27,04 & & \\
\hline Comprimento do talvegue $(\mathrm{km})$ & 9,28 & & \\
\hline Declividade (m/km) & 5,82 & & \\
\hline $\mathrm{CN}$ & 70 & 87 & 98 \\
\hline Potencial de infiltração S (-) & 108,86 & 38 & 5,18 \\
\hline Área impermeabilizada $\left(\mathrm{km}^{2}\right)$ & 0,80 & 16,76 & 24,34 \\
\hline Porcentagem de área impermeável (\%) & 2,96 & 62 & 90 \\
\hline Tempo de concentração (h) & 1,65 & 0,72 & 0,65 \\
\hline
\end{tabular}

Tabela 2: Parâmetros para simulação dos hidrogramas de cheia da bacia hidrográfica do igarapé Urumari para os cenários de 1960, 2017 e futuro.

Assim, com os dados da Figura 4 e da Tabela 2, elaboraram-se os hidrogramas de cheia (Figura 8) para os 3 cenários analisados da bacia hidrográfica do igarapé Urumari. A Figura 8 mostra a comparação dos hidrogramas resultantes dos diferentes cenários analisados, podendo-se observar o aumento da vazão de pico, tendo como causa principal o avanço do processo de urbanização da bacia. Os hidrogramas de cheia deixam clara a relação entre vazão de pico e impermeabilização do solo, assim como o escoamento superficial e o tempo de concentração, que diminui para os cenários 2017 e futuro (Tabela 2), também estão 
correlacionados com o uso do solo das bacias hidrográficas. De acordo com Rezende et a. (2015), quanto maior a impermeabilização, menor será o tempo de concentração.

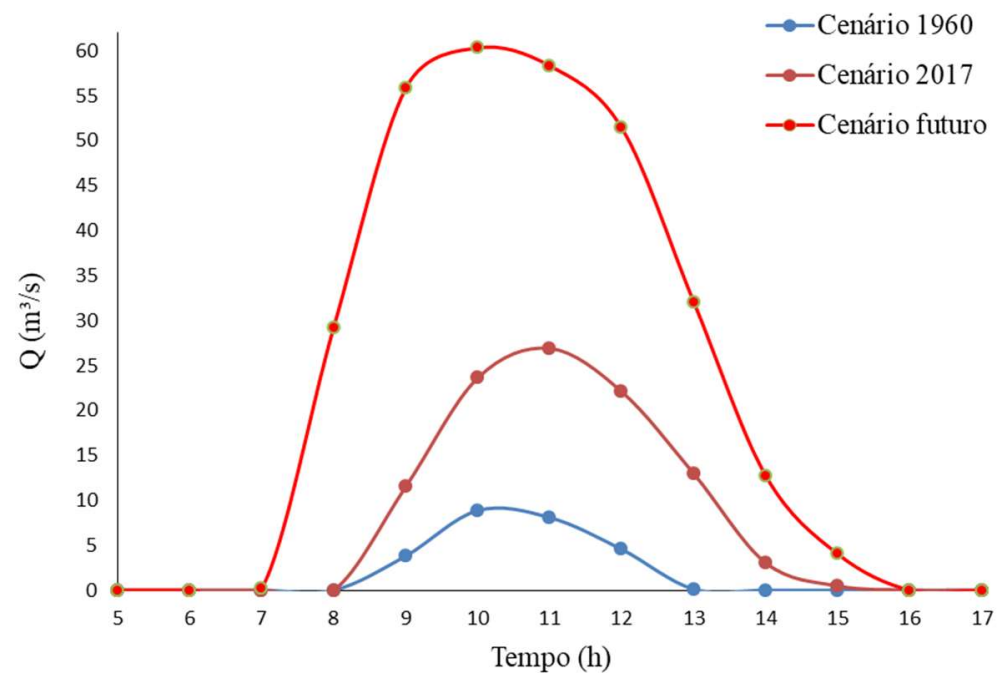

Figura 8: Hidrogramas de cheia para os diferentes cenários de ocupação do solo da bacia do igarapé Urumari.

No cenário 1960, os resultados indicam que apenas 7,34\% do total precipitado foram transformados em escoamento superficial, mostrando que grande parte do volume de chuva infiltrasse no solo. No cenário 2017, o volume transformado em escoamento chegou a 34,87\% e no cenário futuro, os resultados mostram que $82,95 \%$ do total precipitado serão transformados em escoamento superficial, devido ao nível de impermeabilização do solo. Os três cenários urbanos simulados, apresentaram resultados diferentes para o mesmo evento de chuva. A diferença entre seus potenciais de infiltração implicou na geração de maior volume de escoamento e maior vazão de pico nos cenários com maior impermeabilização do solo.

Segundo Bianchi (2012), o aumento da vazão está relacionado ao aumento do escoamento superficial causado pela impermeabilização do solo, o qual é diretamente influenciado pela redução das florestas e crescimento da área urbana. A vazão de pico no cenário de 1960 foi de $8,9 \mathrm{~m}^{3} / \mathrm{s}$ e no cenário de 2017 foi igual a $26,9 \mathrm{~m}^{3} / \mathrm{s}$, ou seja, a vazão mais que triplica. Comparando-se o cenário de 2017 com o cenário futuro, que apresentou uma vazão de pico de $60,3 \mathrm{~m}^{3} / \mathrm{s}$, tem-se um aumento de mais de $100 \%$ da vazão. Estes valores podem ser correlacionados com os percentuais de aumento da impermeabilização do solo, pois no cenário 1960, o percentual de área impermeável era de apenas 2,96\% do total da área de drenagem da bacia, passando para o cenário 2017 com 62\% de área impermeável e do cenário 2017 para o cenário futuro, passando para 90\%, impactando no aumento da vazão de pico. Nesse contexto, também Rezende et al. (2015) observam que esse é um dos efeitos da urbanização vinculada à impermeabilização do solo, ou seja, o aumento da vazão máxima.

Pode-se observar também, que o potencial de infiltração apresentou uma diminuição de 108,86 do cenário 1960 para 38 no cenário 2017, caracterizando uma redução de 65,10 \% em sua capacidade de infiltração. Assim como, do cenário 2017 para o cenário futuro, o potencial de infiltração diminuiu de 38 para 5,18 , caracterizando uma redução de 86,37 \% em sua capacidade de infiltração. Sob esta ótica, Justino et al. (2011) afirmam que a impermeabilização de 7\% da área dos lotes já acarreta a duplicação do escoamento 
superficial e que casos mais extremos, como a impermeabilização de $80 \%$ do lote, gera um volume de escoamento superficial oito vezes maior, contudo, isso depende do grau de urbanização da área estudada.

Em relação ao tempo de concentração observado nos três cenários, pode-se verificar que, no cenário de 1960, no qual a bacia do igarapé Urumari possuía 2,96\% de área impermeável, o tempo de concentração era de 1,65 h; e no cenário de 2017, com $62 \%$ de área impermeável, o mesmo passou a ser de 0,72 h, uma redução de 0,93 h do tempo de concentração neste período. Já no cenário futuro, com $90 \%$ de área impermeável, o valor do tempo de concentração será de 0,65 h, ou seja, uma redução de 1 h entre 1960 e o cenário futuro. A diminuição do tempo de concentração da bacia também é causada pela impermeabilização do solo, que acaba aumentando a velocidade da água escoada em direção ao seu exutório, podendo causar vítimas e danos materiais.

\section{CONCLUSÃO}

O avanço da urbanização vinculada ao aumento de impermeabilização do solo ocasiona a diminuição do tempo de concentração e o aumento da vazão de pico, parâmetros que podem gerar a ocorrência de alagamentos de ruas quando atrelados a um sistema de drenagem pluvial mal dimensionado. Constatação que se apoia na simulação dos hidrogramas de cheia simulados para os três diferentes cenários, mostrando o efeito da evolução urbana sobre a vazão de pico na bacia hidrográfica do igarapé Urumari para um evento de chuva intensa. Nesse caso, o cenário futuro, por ter maior impermeabilização do solo, apresenta uma vazão de escoamento aproximadamente 2,24 vezes maior que a vazão de pico do cenário de 2017 e aproximadamente 6,80 vezes maior que a do cenário de 1960. Em relação ao potencial de infiltração, observou-se uma diminuição de 108,86 para 5,18, do cenário de 1960 para o cenário futuro, ou seja, um decréscimo de 95,24 \%. Acredita-se que esta redução deu-se, além da alta impermeabilização do solo, à diminuição da cobertura vegetal.

O cenário de 2017 foi base para obtenção das características reais da bacia do igarapé Urumari, sendo este o cenário em que a cidade de Santarém vive hoje, ou seja, é o cenário com o qual a população convive nos períodos de fortes precipitações, com alagamentos de ruas, entre outros transtornos provenientes, independente das vias afetadas apresentarem ou não pavimentação. No caso do cenário futuro, optou-se por considerar a porcentagem de área impermeabilizada, sem estimar o tempo que levará para que esta urbanização seja concretizada, pois o mais importante é a estimativa deste percentual para o futuro, o qual resultou em $90 \%$, o que certamente acarretará aumento do volume escoado e da vazão de pico, em relação ao cenário de 2017. Isso pode ser considerado como um alerta para os gestores municipais no que se refere ao planejamento e controle das políticas urbanas em relação à rede de drenagem de águas pluviais, que deverá ser norteada em concordância com os estudos da expansão urbana nesta área.

Os resultados apresentados neste trabalho mostram a importância de se conhecer a vazão de pico para dimensionar projetos de rede drenagem e infraestrutura urbana. $O$ uso do solo é determinante para o dimensionamento da rede de drenagem pluvial, tendo em vista que as áreas mais impermeabilizadas acarretam maior escoamento superficial e vazão de pico. Neste trabalho foi considerado apenas um evento 
de chuva, devido à falta de dados pluviométricos de períodos passados. Seria interessante que houvesse um maior monitoramento desses eventos para que futuramente possa ser possível estimar com maior precisão os parâmetros necessários para o cálculo de hidrogramas de cheia das bacias urbanas de Santarém. Fato que se repete em outras cidades do Brasil e do mundo.

\section{REFERÊNCIAS}

ALMEIDA, I. K.; ANACHE, J. A. A.; ALMEIDA, V. R.; SOBRINHO, T. A.. Estimativa de tempo de concentração em bacia hidrográfica. In: SIMPÓSIO BRASILEIRO DE RECURSOS HÍDRICOS, 20. Anais. Bento Gonçalves: Fundaparque, 2013.

BARROS, A. M.; NEVES, M. G. F. P.; HENRIQUE, D. C.. Variabilidade e causas na geração de vazão em bacias urbanas: estudo de caso do Riacho do Sapo, Maceió-AL. Revista Eletrônica de Gestão e Tecnologias Ambientais, Salvador, v.4, n.15, p.220-231, 2016. Dol: http://dx.doi.org/10.9771/gesta.v4i2.15636

BENINI, R. M.; MENDIONDO, E. M.. Urbanização e impactos no ciclo hidrológico na Bacia do Mineirinho. Floresta e Ambiente, Seropédica, v.22, n.2, p.211-222, 2015. DOI: http://dx.doi.org/10.1590/2179-8087.103114

BIANCHI, R. C.; RIZZI, N. E.; GUIMARÃES, R. Z.; SCHECHI, R. G.. Estimativa da Vazão Máxima da Bacia Hidrográfica do Rio Canguiri através do Método de Ven Te Chow. Raega - 0 Espaço Geográfico em Análise, Curitiba, n.25, p.164-185, 2012.

CHANG, M. M.; PINHEIRO, H. D.; LOPES, D. D.. Simulação do escoamento superficial de uma área pré e pós urbanização. Ciência e Natura, Santa Maria, v.37, n.4, p.198-209, 2015. DOI: http://dx.doi.org/105902/2179460X17276

FARIA, N. O.; BARBASSA, A. P.; SILVEIRA, A.. Monitoramento, modelagem e simulação de cenários para a Bacia do Córrego Barbado - Cuiabá/MT. Revista Brasileira de Recursos Hídricos, Porto Alegre, v.19, n.1, p.165-176, 2014. DOI: http://doi.org/10.21168/rbrh.v19n1.p165-176

FERNANDES, R. O.; COSTA, C. T. F.; STUDART, T. M. C.. Análise de sensibilidade em hidrogramas de cheias máximas obtidos pelo método do SCS em uma bacia urbana. Revista Águas Subterrâneas, São Paulo, v.31, n.3, 2017. DOI: http://doi.org/10.14295/ras.v31i3.28812

FERREIRA, M. E. M. S.. Saneamento Ambiental e Urbanização da Amazônia: O Caso das Comunidades de Bela Vista I e II Próximas da Área de Proteção Ambiental/APA Saubal - Santarém/Pará. Dissertação (Mestrado Profissional em Processos Construtivos e Saneamento Urbano) - Universidade Federal do Pará, Belém, 2016.

FREITAS, L. F.; GUIMARÃES, R. F.; de CARVALHO JUNIOR, O. A.; GOMES, R. A. T.. Relacionamento entre a mudança da rede de drenagem devido à construção de estruturas urbanas e o surgimento de voçorocas e ravinas no bairro do Jardim Botânico no Distrito Federal. Revista Brasileira de Geomorfologia, Brasília, v.13, n.4, p.419-433, 2012. DOI: http://dx.doi.org/10.20502/rbg.v13i4.294
GERMANO, A; TUCCI, C. E. M; SILVEIRA, A. L. L.. Estimativa dos Parâmetros do Modelo IPH-II para Algumas Bacias Urbanas Brasileiras. Revista Brasileira de Recursos Hídricos, Porto Alegre, v.3, n.4, p.103-120.1998. DOI: http://doi.org/10.21168/rbrh.v3n4.p103-120

JUSTINO, E. A.; PAULA, H. M.; PAIVA, E. C. R.. Análise do efeito da impermeabilização dos solos urbanos na drenagem de água pluvial do município de Uberlândia-MG. Espaço em Revista, Goiânia, v.13, n.2, p.16-38, 2011. DOI: http://doi.org/10.5216/er.v13i2.16884

NUNES, F. G.; FIORI, A. P. Análise da impermeabilização dos solos e aumento dos picos de vazão de cheias em bacias hidrográficas urbanas. Boletim Paranaense de Geociências, Curitiba, n.62-63, p.47-60, 2008. DOI: http://dx.doi.org/10.5380/geo.v62i0.7704

Oliveira, J. M. G. C.. Expansão urbana e periferização de Santarém-PA, Brasil: questões para o planejamento urbano. In: COLÓQUIO INTERNACIONAL DE GEOCRÍTICA, 10. Anais. Barcelona: Universidad de Barcelona, 2008. DOI: http://www.ub.es/geocrit/-xcol/268.htm

PIMENTEL, D. R.; MELO, S.. Proteção ambiental no igarapé do Urumari, cidade de Santarém, Pará, Brasil. Revista Em Foco, Santarém, v.1, n.22, 2014.

RAYOL, B. P.; ALVINO-RAYOL, F. O.. Desenvolvimento inicial de mudas de espécies arbóreas em sistemas agroflorestais do Baixo Amazonas, Estado do Pará, Brasil. In: CONGRESSO LATINOAMERICANO DE AGROECOLOGIA, 5. Anais. La Plata, 2015.

REZENDE, G. B. M.; ARAÚJO, S. M. S.. Análise da taxa de impermeabilização e tempo de concentração nas sub-bacias da área urbana de Barra do Garças - MT, Pontal do Araguaia - MT e Aragarças - GO. Revista Verde de Agroecologia e Desenvolvimento Sustentável, Pombal, v.10, n.5, p.27-37, 2015.

SANTARÉM. Lei Complementar 007/2012: Dispõe sobre o Parcelamento, Uso e Ocupação do Solo do Município de Santarém. 2012.

SANTOS, F. M.; LOLLO; J. A.. Cartografia digital para estimativa de escoamento superficial visando ao planejamento urbano. Engenharia Sanitária e Ambiental, Rio de Janeiro, v.21, n.4, p.663-675, 2016. DOI: http://dx.doi.org/10.1590/s1413-41522016130053

SANTOS, K. A.; RUFINO, I. A. A.; FILHO, M.. Normando Macêdo Barros. Impactos da ocupação urbana na permeabilidade do solo: o caso de uma área de urbanização consolidada em Campina Grande - PB. Engenharia Sanitária e Ambiental, Rio de Janeiro, v.22, n.5, p.943-952, 2017. DOI: http://dx.doi.org/10.1590/s1413-41522016146661 
SANTOS, P. L.; OLIVEIRA JR, R. C.; RODRIGUES, T. E.. Mapa de reconhecimento dos solos do Planalto de Santarém, Estado do Pará. Escala 1:2000.000. Belém: EMBRAPA, 2002.

A CBPC - Companhia Brasileira de Produção Científica (CNPJ: 11.221.422/0001-03) detém os direitos materiais desta publicação. Os direitos referem-se à publicação do trabalho em qualquer parte do mundo, incluindo os direitos às renovações, expansões e disseminações da contribuição, bem como outros direitos subsidiários. Todos os trabalhos publicados eletronicamente poderão posteriormente ser publicados em coletâneas impressas sob coordenação da Sustenere Publishing, da Companhia Brasileira de Produção Científica e seus parceiros autorizados. Os (as) autores (as) preservam os direitos autorais, mas não têm permissão para a publicação da contribuição em outro meio, impresso ou digital, em português ou em tradução. 